\title{
Jazz and the art of conversation
}

Previously published at www.cmaj.ca

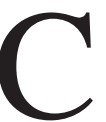

an Duke Ellington improve your diagnoses? Will Miles Davis ease your exams? Dr. Paul Haidet offers an emphatic Yes. Music, he says, can teach doctors to listen deeply. Particularly Jazz.

Jazz is intrinsically tied to the idea of improvisation. Players riff off a previous idea, stylistically darting on a dime before picking up on an unexpected rhythmic course. It's what gives the genre its flavour and distinction. Such "beautiful music" can find its way into the examining room too, if doctors learn to work in concert with their patients to develop an alert and empathetic communication style.

That's the conclusion that Haidet came to almost a decade ago. He's now the director of medical education research at Pennsylvania State University in Hershey, Pennsylvania, where he teaches a course called Jazz and the Art of Medicine: Improvisation in the Medical Encounter.

A jazz DJ in college, Haidet initially made the connection between jazz and medicine while he was at a communications course. "The way that doctors and patients talk in some ways is similar to the way jazz musicians communicate on the bandstand," he says. In each case, both encounters are improvised, yet there is some sort of structure imposed on the exchange. Haidet recently wrote that "rather than take up all the space in the conversation with strings of 'yes/no' questions ... I find that I am at my best when I can give patients space to say what they want to say, gently leading patients through the telling of their illness narrative from their perspective, rather than forcing their narrative to follow my biomedical perspective."

"It takes listening aligned toward understanding, not just the collection of factual data."

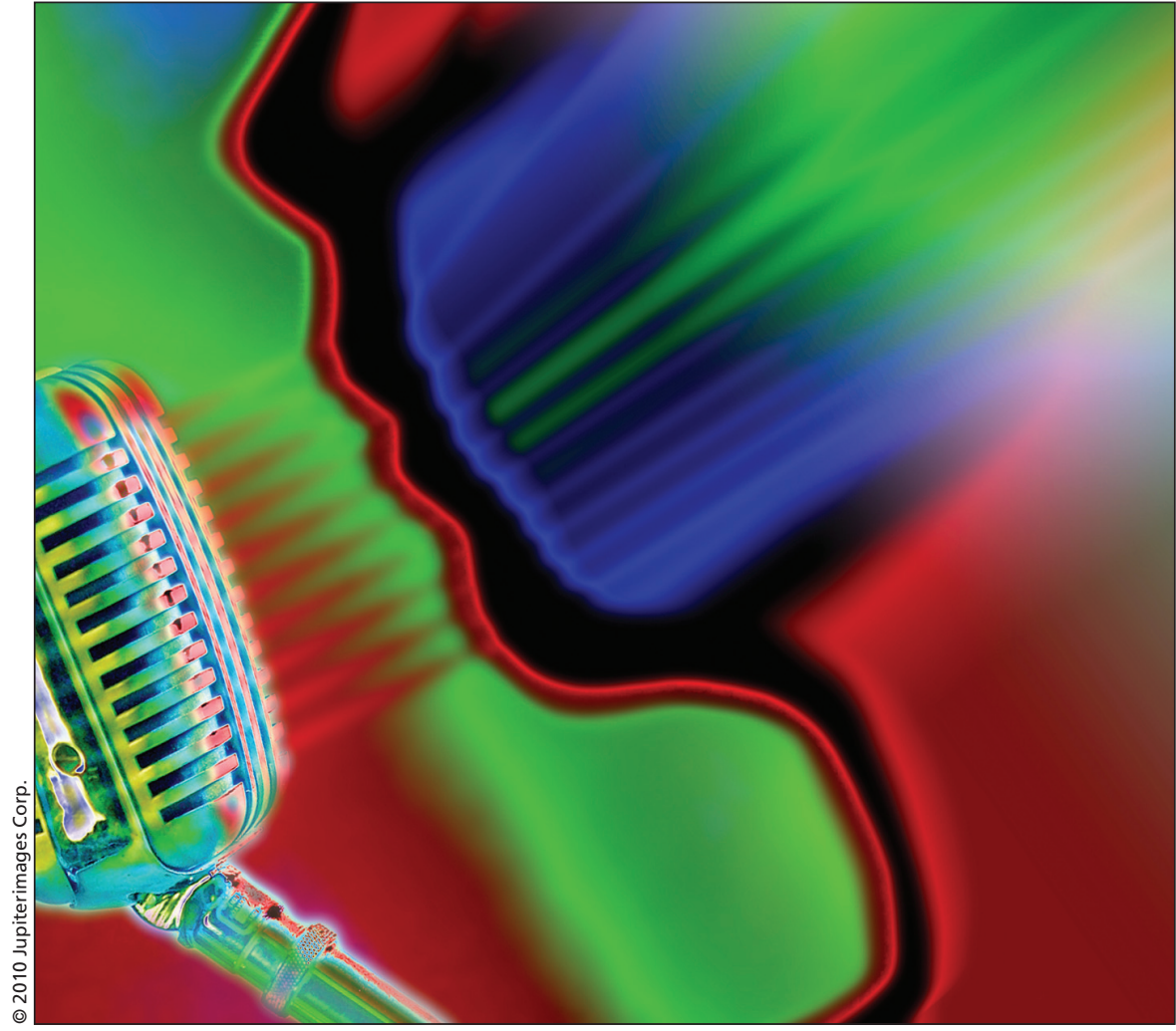

Taught previously at Baylor College of Medicine, Houston, Texas, and Mount Sinai Hospital, New York City, New York, his one-and-a-half-hour course involves watching two, sevenminute videos on doctor-patient encounters. One shows the doctor with a high-control style; the other has more of a narrative exchange.

Jazz-listening exercises are interspersed. With the music as a guide, Haidet emphasizes the importance of space, latency (the time between talking) and pace (Box 1). Discussions follow and it becomes obvious that in the less-controlling video, the biomedical diagnosis develops very quickly (Box 2).

"It also provides a number of moments where there's a deep connection between the doctor and patient," Haidet says. "You can really see that the patient leaves feeling that the doctor really understands her."

While it's both effective and emotionally satisfying, medical communications research often has a Pollyannaish tone. In real-life situations, is there time and a need to develop a deep connection with each patient? Haidet acknowledges the time crunch, but says strong communication skills can be time-efficient.

Research supports his theory. While it's widely documented that doctors interrupt patients on average after 18 seconds, ${ }^{2}$ it's not often mentioned that in the same study, researchers Frankel and Beckman found in the rare instances when doctors did not interrupt, the patient was finished speaking after about two minutes.

While this may seem like an eternity when there are less than 15 minutes allotted per patient, those two minutes can give doctors a chance to tune into 
nonverbal signals and fleeting glimpses of emotion - telling clues that they can then follow up on. "That expression lets the patient know not only that you've understood what they've said, but you have understood on a deeper level," Haidet says.

He notes that many doctors working at inner-city public hospitals learn to achieve a level of connection and understanding in a short time.

Box 1: Suggested listening

- Now's the Time, Sonny Stitt (alto saxophone) from Stitt Plays Bird (Atlantic/Warner)

- All Blues, Miles Davis (trumpet) from Kind of Blue (Sony/BMG)

- Giant Steps, John Coltrane (tenor saxophone) from Giant Steps (Atlantic/Warner)

- Waltz For Debby, Bill Evans (piano), Scott LaFaro (bass) from The Best of Bill Evans (Fantasy Inc.)
"They're very good at getting centred and being in the moment with those patients," he says. "They listen deeply and co-construct the narrative with the patient."

It's not a one-way street. Haidet also

\section{Box 2: Clinical exercises}

1. "Mastering space"

For the next two weeks, pick one time when the patient is finishing a sentence. Wait for at least 10 seconds before saying anything. If the patient talks before 10 seconds, follow up on what they say. Watch for the times when the patient says something unexpected or profound.

2. "Cultivating ensemble"

For the next two weeks, say a sentence that begins with: "So, what I'm hearing you say is... " Do this once with every patient. After two weeks, do it when it feels right. Experiment with different ways of saying the phrase. notes that patients need to be assertive - and studies support that theory. In many cases, "interventions were associated with improved physician and patient communication behaviors." 3

In reviews of Haidet's course, doctors remarked that while most of what they learned wasn't new to them, the material allowed them to enjoy their practice much more.

\section{Fateema Sayani BJ}

Music critic

Ottawa, Ont.

\section{REFERENCES}

1. Haidet P. Jazz and the 'art' of medicine: improvisation in the medical encounter. Ann Fam Med 2007;5:164-9.

2. Beckman HB, Frankel RM. The effect of physician behavior on the collection of data. Ann Intern Med 1984:101:692-6.

3. Rao JK, Anderson LA, Inui TS, et al. Communications interventions make a difference in conversations between physicians and patients: a systematic review of the evidence. Med Care 2007;45:340-9.

\section{A commentary on the truth}

Previously published at www.cmaj.ca

The orange wire problem and other tales from the doctor's office

David Watts

University of lowa Press; 2009.

186 pp $\$ 25.00$

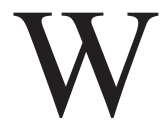
riting reflective essays about clinical experiences is a complex endeavour that can appear deceptively simple.

It is not always easy to balance fidelity to the facts with the imperative to maintain patient confidentiality. There are the ethical questions of what benefits are accrued, and to whom, and what the risks might be. There is the matter of choosing your audience and deciding how best to speak to them.

The number of physicians who write despite these difficulties is quite striking and while not everyone possesses

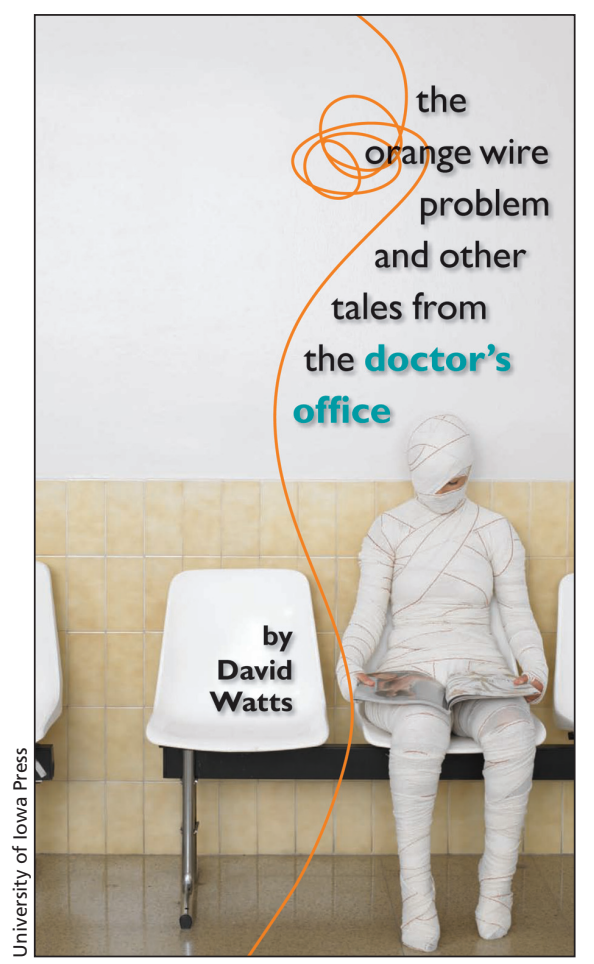

the same degree of skill, there is generally an earnest quality to the writing that suggests an effort to understand, and to share, truth.

San Francisco, California, physician David Watts takes this task seriously. As well as authoring several books on medicine, he is a poet, musician, and television personality. In the preface to The orange wire problem and other tales from the doctor's office he writes that he is striving "not so much to document as to approach a truth that goes beyond nonfiction and dares to flirt with the realm of mystery." As such a statement would suggest, this is an ambitious book.

In 26 short narratives, Watts provides sparse sketches of encounters between doctor and patient. Most of the clinical scenarios will be familiar to physicians, but Watts imbues them with importance and significance. He brings himself deeply into the encounters and 